Seventh Symposium on Advanced Medicine

Edited by IAN A. D. Bouchier. Proceedings of a Conference held at the Royal College of Physicians, London, February 1971. Pp. 345, illustrated. London: Pitman Medical, 1971. £3.00.

This book reports one of the series of symposia held at the Royal College of Physicians, London. It appears only 5 months after the meeting was held and the Editor and publishers are to be congratulated on this achievement.

The symposium was concerned with six major sections including Cardiovascular Disorders, Genetics, Nervous System, Stress in Society, Haematology and Renal Diseases. In each case, four papers on some aspect of the picture were included and the contributions of J. Green (The Control of Cholesterol Metabolism), G. R. Fearnley (Fibrinolysis) and J. J. Brown and his colleagues on the Renin-Angiotensin System in Hypertension, were noteworthy. The Lumleian, Langdown Brown and Lilly Lectures were additional features.

The book is printed by photolithography and is presented in a soft cover. There are few illustrations and those that are included are indifferently reproduced. Although the subject matter is extensive and well referenced, the standard of presentation varies considerably among the papers, from those that would do credit to an International meeting and those that are more literary than scientific in nature. It is also hoped that in future some discussion will be included after the papers.

The underlying philosophy of the symposium is not very clear and the selection of subjects would appear to be haphazard. This has resulted in a publication of general rather than specialized interest which is perhaps an appropriate means of representing progress in medicine on several fronts, Nevertheless, it does detract slightly from its scientific value. Since the symposia are part of a continuing series it might have been preferable to devote the whole of one meeting to a single subject. However, the considerable coverage of so $\stackrel{\mathbb{Q}}{2}$ many diverse aspects of medicine has resulted in a book which $C$ deserves the attention of post-graduate doctors and which $\vec{\exists}$ would be a useful addition to medical libraries.

\section{A Colour Atlas of General Pathology}

By G. Austin Gresham. Pp. 365, illustrated. London: $\overline{\bar{c}}$ Wolfe Medical Books, 1971. £3.75.

When dealing with a pictorial subject such as pathology a text book has to find a balance between words and pictures. Three pages of text accompanied by one micrograph is hard $\overrightarrow{0}$ work for the student and no matter how well the book is? written the description of a microscopic phenomenon can $\overrightarrow{\vec{H}}$ never replace a good micrograph illustrating the phenome- $\omega$ non. Conversely an atlas consisting of a collection of micro- $\frac{}{\partial}$ graphs, no matter how good, cannot convey the necessary information to the student if there is not sufficient, elucidatory 3 . text. Unfortunately, this book would seem to come into the $+\vec{D}$ latter category. As a concept it is first class, a lavish and $\infty$ beautiful collection of micrographs all in full colour showing of not only the scientific aspects of histopathology but also the great artistic merit of many micrographs. However, there does $\vec{N}$ not seem to be sufficient text accompanying the micrographs 0 and what there is could occasionally even be misleading to the medical or biological student for whom it is written. In 음 spite of this, students could find the book useful for end of term revision and also it could be a useful adjunct to a more conventional pathology book by reason of the numerous $\mathbb{D}$ micrographs.

On the technical side a minority of micrographs have poor $\frac{2}{2}$ colour rendition and there is an occasional inconsistenfy between legend and micrograph In spite of all this, the bog is pleasing to the eye and a student hard pressed for tine could find it useful for a quick revision of the term's workō? 